\title{
Cost effectiveness of vildagliptin versus glimepiride as add-on treatment to metformin for the treatment of diabetes mellitus type 2 patients in Greece
}

\author{
Hara Kousoulakou ${ }^{1 \dagger}$, Magdalini Hatzikou ${ }^{2 \dagger}$, Varvara Baroutsou ${ }^{2 \dagger}$ and John Yfantopoulos ${ }^{3,4^{* \dagger}}$
}

\begin{abstract}
Objectives: This study was designed to assess the cost-effectiveness of vildagliptin versus glimepiride as add-on to metformin in the management of type 2 diabetes mellitus (T2DM) patients in the Greek healthcare setting.

Methods: A cost-effectiveness model was designed, using MS Excel, to compare two treatment strategies. Strategy 1 consisted of first-line metformin, followed by metformin + vildagliptin in second-line, while strategy 2 consisted of first line metformin, followed by metformin + glimepiride in second line. Subsequent lines were the same in both strategies and consisted of metformin + basal insulin and metformin + basal + rapid insulin. Clinical data and utility decrements relating to diabetes complications were taken from the published literature. Only direct medical costs were included in the analysis (cost base year 2014), and consisted of drug, adverse events and comorbidity costs (taken from local officially published sources and the literature). The perspective adopted was that of the Social Insurance Fund. The time horizon was lifetime, and future costs and outcomes were discounted at 3.5\% per annum.

Results: Adding vildagliptin to metformin increased drug costs compared with adding glimepiride to metformin (€2853 vs. €2427, respectively). However, this increase was offset by a decrease in the costs of associated comorbidities (€4393 vs. €4539) and adverse events (€2757 vs. €3111), resulting in a lower total cost of $€ 74$ in strategy 1 compared with strategy 2. Comorbidities were the largest cost component in both strategies, accounting for 43.9 and $45.0 \%$ in strategies 1 and 2, respectively. Strategy 1 was also associated with increased life-years (LYS, 0.11) and quality-adjusted life-years (QALYs, 0.11) compared with strategy 2. Strategy 1 is therefore dominant, as it is associated with both lower overall costs and increased effectiveness.
\end{abstract}

Conclusions: Vildagliptin as add-on treatment to metformin in the management of T2DM in Greece appears to be dominant versus. glimepiride in terms of both cost per LY and cost per QALY gained.

Keywords: Vildagliptin, Type 2 diabetes mellitus, Cost-effectiveness, Greece

\section{Background}

Type 2 diabetes mellitus (T2DM) comprises $90 \%$ of people with diabetes around the world, and is largely the result of excess body weight and physical inactivity [1]. Over the past decades, T2DM has become an epidemic

\footnotetext{
*Correspondence: yfantopoulos@gmail.com

${ }^{\dagger}$ Hara Kousoulakou, Magdalini Hatzikou, Varvara Baroutsou and John

Yfantopoulos have contributed equally to the study

${ }^{4}$ School of Economics and Political Science, Athens, Greece

Full list of author information is available at the end of the article
}

[2] and affects about $6 \%$ of the adult population in the western world [3]. In Greece, the projected prevalence of $\mathrm{T} 2 \mathrm{DM}$ in 2002 was estimated at $7.6 \%$ in men and $5.9 \%$ in women [4].

T2DM is a costly disease. It is associated with significant burden due to specific diabetes-related microvascular complications, increased risk of macrovascular complications (ischemic heart disease, stroke and peripheral vascular disease), blindness, renal failure and amputations [5-7]. The American Diabetes Association (ADA) 
estimated the total cost of diabetes in the US at $\$ 174$ billion in 2007 [8]. A recent Greek study estimated the total annual cost per patient for managing T2DM in Greece at $€ 7111$ [9].

International guidelines recommend therapy in individuals with $\mathrm{T} 2 \mathrm{DM}$ to target $\mathrm{HbA} 1 \mathrm{c} \leq 7 \%$ to minimize micro- and macrovascular risk [10]. A target of HbA1c $\leq 6.5 \%$ may be considered in some patients with T2DM, but this must be balanced against the risk of hypoglycemic events $[11,12]$, which represent a significant economic burden [13].

In a randomized, open-label, comparative study vildagliptin-metformin treatment provided blood glucose control efficacy comparable to that of glimepiride-metformin treatment and resulted in better adverse event profile with lower risks of hypoglycemia and weight gain [14]. Another study showed that when metformin monotherapy fails to maintain sufficient glycaemic control, the addition of vildagliptin provides comparable efficacy to that of glimepiride, with a favourable safety profile and significant reduction in hypoglycaemia compared with glimepiride [15].

Therefore, it was deemed necessary to investigate the additional costs associated with the additional benefits of vildagliptin-metformin in the management of T2DM, since payers are increasingly interested in the economic evaluation of new health technologies. This study aimed at assessing the cost effectiveness of vildagliptin versus glimepiride as add-on to metformin in the Greek healthcare setting.

\section{Methods}

\section{Model design}

A cost-effectiveness patient simulation model was developed in Excel ${ }^{\circledR}$ based on the risk equations from the UK Prospective Diabetes Study (UKPDS) Outcomes model [16]. During each cycle a patient could experience any of the following complications: ischemic heart disease, myocardial infarction, congestive heart failure, renal failure, stroke, amputation. The model is described in detail elsewhere [17].

A cohort of 10,000 patients who failed to achieve glycemic control with metformin monotherapy entered the model. Baseline characteristics were assumed to be the same for both cohort models and were based on the Diabetes Atlas of the International Diabetes Federation [18]. Mean patient age at model start was 63 years.

Two treatment strategies were compared in the model: strategy 1 in which vildagliptin is added to metformin in 2nd line treatment and strategy 2 in which glimepiride is added to metformin in 2nd line treatment (Table 1). The HbA1c threshold (7\%) based on which patients were
Table 1 Treatment strategies

\begin{tabular}{lll}
\hline & Strategy 1 & Strategy 2 \\
\hline 1st line treatment & Metformin & Metformin \\
2nd line treatment & $\begin{array}{c}\text { Metformin + vilda- } \\
\text { gliptin }\end{array}$ & Metformin + glimepiride \\
3rd line treatment & $\begin{array}{c}\text { Metformin + basal } \\
\text { insulin }\end{array}$ & Metformin + basal insulin \\
4th line treatment & $\begin{array}{c}\text { Metformin + intensive } \\
\text { insulin }\end{array}$ & $\begin{array}{c}\text { Metformin + intensive } \\
\text { insulin }\end{array}$ \\
\hline
\end{tabular}

switched to the next in line treatment was taken from the Hellenic Diabetes Association guidelines [19].

The model's time horizon was that of a lifetime and outcomes assessment criteria were Quality Adjusted Life Years (QALYs) and Life Years (LYs). Future costs and outcomes were discounted at $3.5 \%$ per annum, since costeffectiveness results should reflect the present value of the stream of costs and benefits accruing over the time horizon of the analysis [20].

\section{Model inputs \\ Clinical data}

Clinical data on drugs' safety and efficacy, and in particular HbA1c reduction, changes in weight, and incidence rate of hypoglycemic events were extracted from a headto-head clinical trial of vildagliptin and glimepiride in combination with metformin and a published meta-analysis of long-acting insulin analogues versus NPH human insulin $[15,21]$ (Table 2). Outcomes data were extrapolated beyond the trial period with the use of the UKPDS model [16].

\section{Cost data}

The model only considered direct medical costs, which consisted of pharmaceutical, adverse event and comorbidity costs. The perspective adopted was that of the Social Insurance Funds (SIFs) and the cost base year was 2014.

Drug unit costs were based on the Positive Reimbursement List [22]. Annual costs were estimated based on daily dosages and frequency of administration included in the drugs' Summary of Product Characteristics (SPCs) (Table 3).

The cost of monitoring insulin was based on the maximum number of glucose testing strips per patient per month and the respective prices reimbursed by the National Organization for Health Care Services Provision (EOPYY) [23, 24]. The annual cost for patients receiving insulin (basal or intensive) was estimated at $€ 720$, while the respective cost for patients on anti-diabetic treatment without receiving insulin was estimated at $€ 180$ (Table 4). 
Table 2 Efficacy and safety profiles of modelled interventions

\begin{tabular}{|c|c|c|c|c|c|}
\hline & Metformin $^{a}$ & $\begin{array}{l}\text { Meformin + glimepiri- } \\
\text { de }^{a}\end{array}$ & $\begin{array}{l}\text { Metformin + vilda- } \\
\text { gliptin }^{\mathrm{a}}\end{array}$ & $\begin{array}{l}\text { Metformin + basal } \\
\text { insulin }\end{array}$ & $\begin{array}{l}\text { Metformin + intensive } \\
\text { insulin }\end{array}$ \\
\hline $\begin{array}{l}\text { HbA1c initial absolute } \\
1 \text { year change }\end{array}$ & -1.03 & -0.53 & -0.44 & -1.10 & -1.10 \\
\hline $\begin{array}{l}\text { Symptomatic Hypo- } \\
\text { glycaemia Risk (per } \\
\text { year), \% }\end{array}$ & 0.00 & 16.20 & 1.66 & 16.20 & 16.20 \\
\hline $\begin{array}{l}\text { Severe Hypoglycaemia } \\
\text { Risk (per year), } \%\end{array}$ & 0.00 & 1.38 & 0.00 & 3.30 & 3.30 \\
\hline Weight gain (kg/year) & 0.00 & 1.56 & -0.23 & 1.70 & 1.70 \\
\hline
\end{tabular}

a Source: Ferrannini et al. [15]

b Source: Monami et al. [21]

Table 3 Drug costs

\begin{tabular}{lc}
\hline & Annual cost (€) \\
\hline Metformin & 42.10 \\
Metformin + vildagliptin & 593.86 \\
Glimepiride & 35.83 \\
Metformin + glimepiride & 77.93 \\
Basal insulin & 539.16 \\
Metformin + basal insulin & 581.26 \\
Intensive insulin & 494.76 \\
Metformin + intensive insulin $^{\text {a }}$ & 1118.11 \\
\hline
\end{tabular}

a The cost of metformin + intensive insulin is calculated on top of the cost of metformin + basal insulin

Table 4 Insulin monitoring costs per year

\begin{tabular}{ll}
\hline & Monitoring cost (€) \\
\hline Metformin & 180 \\
Meformin + glimepiride & \\
Metformin + vildagliptin & 720 \\
Metformin + basal insulin & \\
Metformin + intensive insulin & \\
\hline
\end{tabular}

The unit costs associated with the management of diabetic complications during first year of treatment, including the cost of severe and non-severe hypoglycemia, were obtained from the Greek Diagnosis Related Groups (DRGs) tariffs [25] and the study by Maniadakis and colleagues [26] (Table 5).

Patient follow-up costs after first year were all calculated based on data from the study by Maniadakis et al. [26] and input from a clinical expert. The estimated costs were subsequently inflated with the Health Price Index [27] to reflect 2014 prices. The cost of renal failure (€36,026 during first year and $€ 21,721$ after first year) was obtained from the study by Stafylas et al. [28].

\section{Utility data}

The utility value for diabetic patients without complications (0.780), as well as the utility decrements relating to ischemic heart disease, myocardial infarction, congestive heart failure, stroke, and amputation were derived from the study by Clarke and colleagues [29]. Disutility data associated with renal failure were obtained from the study by Manns et al. [30], while respective data for weight increase were based on the Dennett et al. study [31] (Table 6).

\section{Sensitivity analysis}

In order to test the robustness of model results, univariate sensitivity analyses were conducted in key variables surrounded by uncertainty. In particular, the following variables were allowed to vary in ranges based on the literature: the HbA1c threshold (between 6.5 and $7.5 \%$ [10]), utility and disutility scores (between 95\% confidence intervals [29]), and discount rates for costs and benefits (between 0 and $8 \%$ [33]).

\section{Results}

The addition of vildagliptin to metformin (strategy 1) increased pharmaceutical cost compared with the addition of glimepiride to metformin (strategy 2) by $€ 426$ (from $€ 2427$ to $€ 2853$ ). However, this was offset by a decrease in the associated comorbidity and adverse event costs, resulting in a lower total cost in strategy 1 $(€ 10,003)$ compared with strategy $2(€ 10,077)$ (Table 7$)$.

Comorbidity costs represented the largest cost component in both strategies (43.9 and $45.0 \%$ in strategies 1 and 2, respectively), while drug costs accounted for 28.5 and $24.1 \%$ of total costs in strategies 1 and 2, respectively (Fig. 1).

Apart from lower overall costs, strategy 1 was also associated with increased LYs (8.07 vs. 7.96 in strategy 2) and QALYs (6.30 vs. 6.19 in strategy 2) (Table 8). Therefore, strategy 1 appears to be dominant, as it is associated 
Table 5 First year and follow up costs

\begin{tabular}{|c|c|c|c|}
\hline & First year event cost $(€)$ & Follow up costs after first year $(€)$ & Source \\
\hline Ischaemic heart disease & 1118 & 933 & $\begin{array}{l}\text { DRG code: N29M \& calculations based on data from } \\
\text { Maniadakis et al. [26] }\end{array}$ \\
\hline Myocardial infarction (non fatal) & 2724 & 1542 & $\begin{array}{l}\text { DRG code: K10X \& calculations based on data from } \\
\text { Maniadakis et al. [26] }\end{array}$ \\
\hline Myocardial infarction (fatal) & 3924 & - & DRG code: K10X + cost of death $€ 1200$ [26] \\
\hline Congestive heart failure & 1868 & 279 & $\begin{array}{l}\text { DRG code: K42M \& calculations based on data from } \\
\text { Maniadakis et al. } 2005 \text { [26] }\end{array}$ \\
\hline Stroke (non fatal) & 2625 & 2100 & $\begin{array}{l}\text { DRG code: N30Mb \& calculations based on data } \\
\text { from Maniadakis et al. [26] }\end{array}$ \\
\hline Stroke (fatal) & 2855 & - & DRG codes: $\mathrm{N} 30 \mathrm{~A}+\mathrm{N} 30 \mathrm{Ma}$ \\
\hline Amputation & 3608 & & DRG code: $\mathrm{K} 13 \mathrm{M}$ \\
\hline Hypoglycemia (non-severe) & 50 & & $\begin{array}{l}\text { Based on clinical expert input (approx. the cost of a } \\
\text { physician consultation) }\end{array}$ \\
\hline Hypoglycemia (severe) & 1735 & & DRG code: $\Theta 20 \mathrm{M}$ \\
\hline Renal failure & 36,026 & 21,721 & Stafylas et al. [28] \\
\hline
\end{tabular}

Table 6 Utility decrements

\begin{tabular}{lll}
\hline Event & Values & Reference \\
\hline Ischemic heart disease & -0.090 & {$[29]$} \\
Myocardial infarction (non fatal) & -0.055 & {$[29]$} \\
Congestive heart failure & -0.108 & {$[29]$} \\
Stroke (non fatal) & -0.164 & {$[29]$} \\
Amputation & -0.280 & {$[29]$} \\
Renal failure & -0.379 & {$[30]$} \\
Symptomatic hypoglycemia risk & -0.014 & {$[32]$} \\
Severe hypoglycemia & -0.047 & {$[32]$} \\
Weight increase (per kg) & -0.002 & {$[31]$} \\
\hline
\end{tabular}

Table 7 Mean per patient costs

\begin{tabular}{lrr}
\hline & Strategy 1 & Strategy 2 \\
\hline Pharmaceutical cost & $€ 2853$ & $€ 2427$ \\
Comorbidities costs & $€ 4393$ & $€ 4539$ \\
Ischaemic heart disease cost & $€ 371$ & $€ 343$ \\
Myocardial infarction cost & $€ 1235$ & $€ 1242$ \\
Congestive heart failure cost & $€ 340$ & $€ 316$ \\
Stroke cost & $€ 1168$ & $€ 1186$ \\
Amputation cost & $€ 36$ & $€ 30$ \\
Renal failure cost & $€ 1243$ & $€ 1422$ \\
Adverse events costs & $€ 2757$ & $€ 3111$ \\
Non-severe hypoglycemia cost & $€ 19$ & $€ 29$ \\
Severe hypoglycemia cost & $€ 126$ & $€ 179$ \\
Monitoring costs & $€ 2611$ & $€ 2903$ \\
Total costs & $€ 10,003$ & $€ 10,077$ \\
\hline
\end{tabular}

with both lower overall costs and increased effectiveness (Fig. 2).

\section{Sensitivity analysis results}

One-way sensitivity analysis confirmed dominance of vildagliptin in most variations of the parameters tested. Model results were most sensitive to changes in the $\mathrm{HbA1c}$ threshold. In particular, increasing the threshold from 7.0 to $7.5 \%$ resulted in vildagliptin being costeffective rather than dominant, however with a very low incremental cost-effectiveness ratio (ICER $=€ 1041$ per QALY gained). Variations of disutility values for comorbidities did not impact significantly model results.

\section{Discussion}

T2DM is a chronic disease, with significant economic and social implications globally. It has been estimated that 347 million people suffer from diabetes worldwide [34], and prevalence exhibits an increasing trend [35]. The annual direct cost of T2DM in eight European countries was estimated at $€ 29$ billion, with an average cost per patient of $€ 2834$ [36]. Therefore, the disease management armamentarium requires effective treatments that can control disease related expenditure. The present study assessed the costs and outcomes of adding vildagliptin to metformin in the management of T2DM in the Greek health care setting and showed that vildagliptin is associated with lower overall costs and increased health outcomes, both in terms of LYs and QALYs gained.

The study further showed that the largest cost component was the management of diabetes-related comorbidities, 


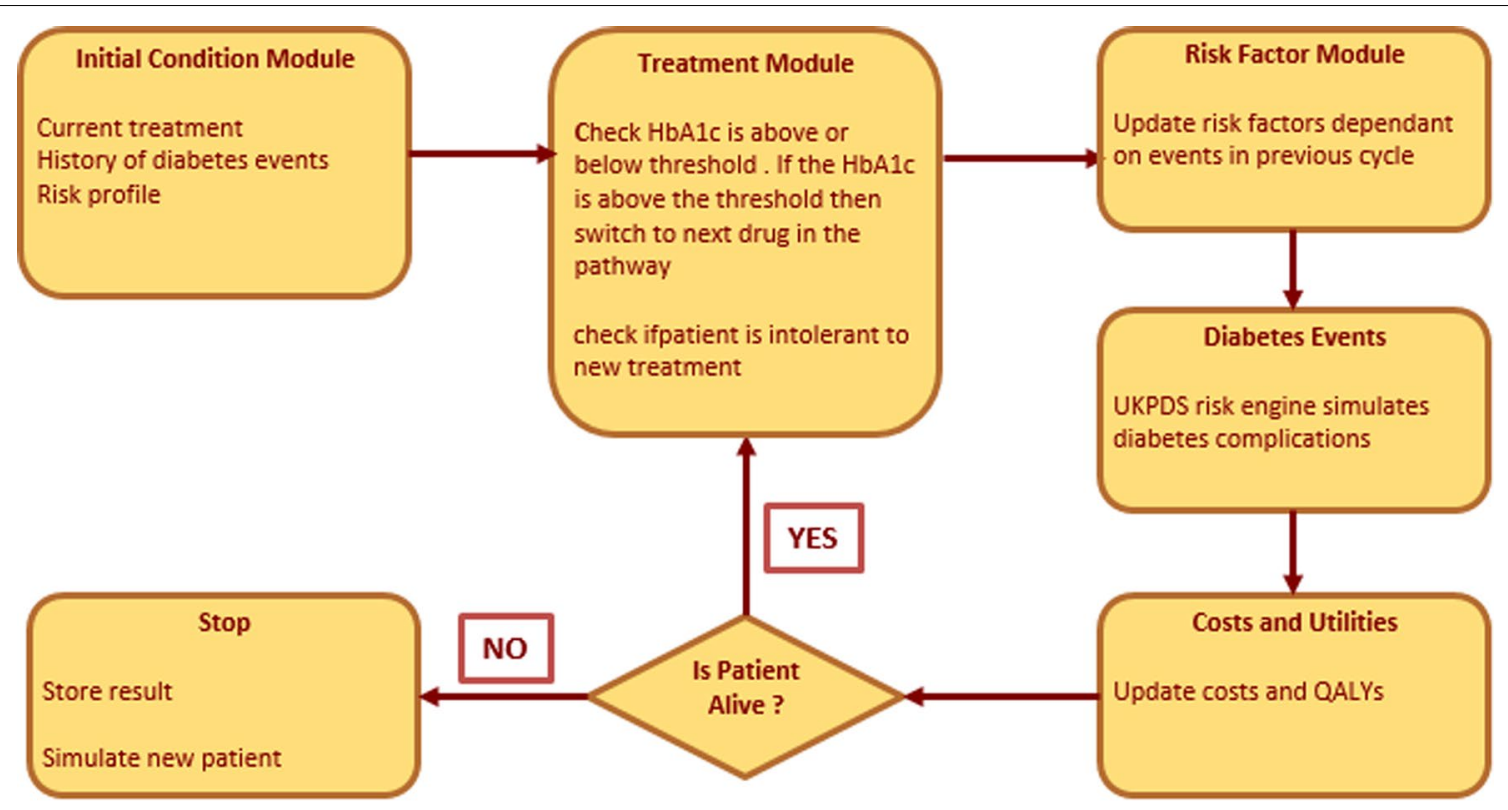

Fig. 1 An overview of the model structure (Source: Clarke et al. [16])

Table 8 Basecase results

\begin{tabular}{llll}
\hline & Strategy 1 & Strategy 2 & Difference (strategy 1 vs. strategy 2) \\
\hline Total costs & $€ 10,003$ & $€ 10,077$ & $-€ 74$ \\
QALYS & 6.30 & 6.19 & 0.11 \\
Life years & 8.07 & 7.96 & 0.11 \\
ICER (cost per QALY gained) & & & Dominant \\
ICER (cost per LY gained) & & & Dominant \\
\hline
\end{tabular}

\section{Strategy 1}

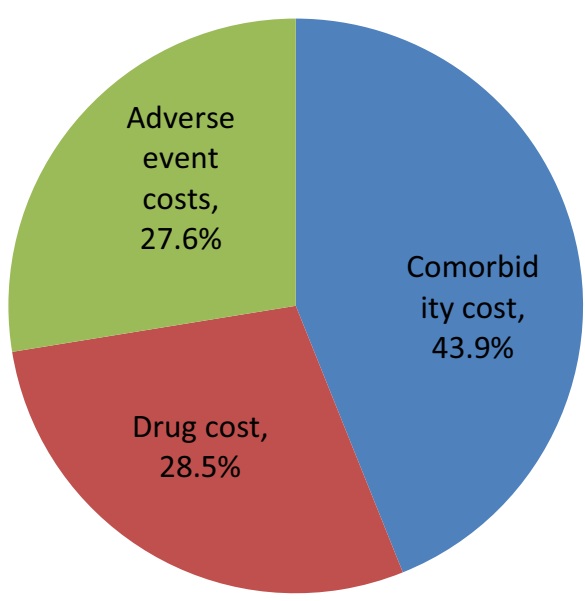

Strategy 2

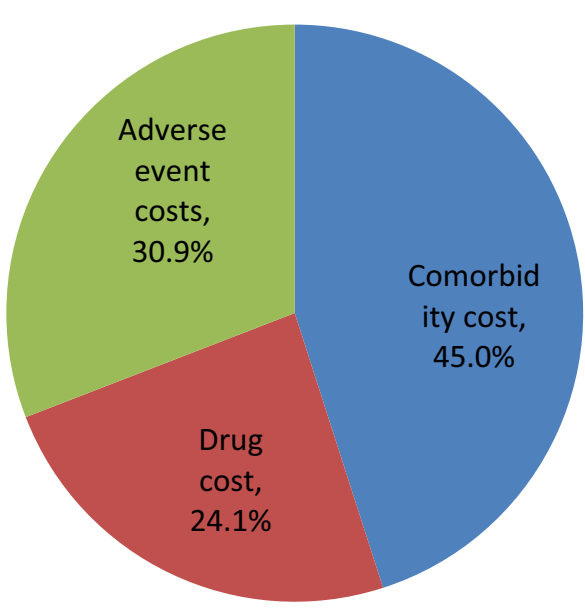

Fig. 2 Cost breakdown 
accounting for approx. $44 \%$ of total costs. This is confirmed by another Greek study which found that management of diabetes related comorbidities accounted for $48 \%$ of costs, while pharmaceutical treatment accounted for 35.9\% [9]. The high cost of managing diabetes comorbidities is further illustrated in the international literature. In the US, mean adjusted total costs for cardiac arrest episodes, cerebrovascular disease with stroke, hypoglycemia, complication, and renal failure episodes have been estimated at $\$ 16,435$; $\$ 4558$; \$445; $\$ 5675$ and $\$ 8765$, respectively [37].

The second most significant cost component was the management of adverse events. Hypoglycemia is a common T2DM adverse events and is considered the key limiting step for optimizing glycemic control [17]. The international literature has shown that both severe and non-severe hypoglycemia incur substantial healthcare costs, and failure to account for these costs may underestimate the value of management strategies that minimize hypoglycemia risk [13]. In the Greek health care setting, severe hypoglycemia costs $€ 1735$ per event and is associated with an average hospitalization length of stay of 18 days [25]. Based on the findings of the present study, adding vildagliptin to metformin is associated with reduced costs for both non-severe (by 34.5\%) and severe (by $29.5 \%$ ) hypoglycemia compared with adding glimepiride to metformin.

The present study had several limitations. First, patient demographics did not reflect the Greek diabetic patient population, but were based on global data. In addition, the model only direct costs were considered in the analysis, reflecting only partly the economic burden of the disease. The ADA has estimated that of the total cost associated with diabetes in the US, $66.7 \%$ is attributed to direct medical costs and $1 / 3$ to reduced productivity [8], thus indirect costs consist a significant cost component.

In addition, the current analysis did not incorporate a number of diabetes-related comorbidities, such as peripheral neuropathy, ulceration and blindness, which are expected to impact significantly the total burden of the disease. Therefore, we can argue that the estimated costs in this study underestimate true disease burden. However, it is expected that inclusion of these comorbidities would not have impacted differently the two model arms (strategy 1 vs. strategy 2), as these would increase proportionately the management cost in both arms, and therefore, would not change model results.

The model which was used in the current economic evaluation analysis has also run with cost inputs from the Portuguese health care setting, where it showed that vildagliptin as add on to metformin is a cost-effective treatment option [17]. Adapting costs to the Greek health care system further favored vildagliptin. Such differences in the model outcomes are anticipated since both the resource use and related unit costs differ from country to country. This is confirmed by the INSTIGATE study, which estimated direct costs in five European countries and showed that the structure of direct cost varies considerably across countries, reflecting the differences in the management, resource use and prices across different health care systems [38].

Decisions in health care need to be based on local data and methods that take into consideration all cost components and not just pharmaceutical costs. The present study showed that although the addition of vildagliptin to metformin increased pharmaceutical costs, it led to a reduction in the overall costs, due to the reduction in the other cost components. Thus, the cost-effectiveness approach implemented could be considered as appropriate, since it adequately represents the complete picture of disease burden in the local setting.

\section{Conclusion}

Vildagliptin as add-on treatment to metformin in the management of T2DM in Greece appears to be dominant versus glimepiride in terms of both cost per LY and cost per QALY gained. Decisions in health care need to be based on local data and methods that take into consideration all cost components and not just pharmaceutical costs. The present study satisfied both these criteria and produced strong results that should be taken into consideration in the decision making process by Health Authorities.

\section{Abbreviations \\ ADA: American Diabetes Association; DRGs: diagnosis related groups; EOPYY: National Organization for Health Care Services Provision, Greece; HbA1c: glycated haemoglobin; LY: life year; NPH: neutral protamine hagedorn; QALY: quality adjusted life year; SIF: social insurance fund; SPC: summary of product characteristic; T2DM: type 2 diabetes mellitus; UKPDS: UK Prospective Diabetes Study.}

\section{Authors' contributions}

All authors read and approved the final manuscript.

\section{Author details}

${ }^{1}$ University of Peloponnese, Damaskinou \& Kolokotroni, 20100 Corinth, Greece. ${ }^{2}$ Novartis Hellas SACI, National Rd, No 1, 12th km, Metamorphosis, 14451 Athens, Greece. ${ }^{3}$ National and Kapodistrian University of Athens, 45 Akadimias, 10672 Athens, Greece. ${ }^{4}$ School of Economics and Political Science, Athens, Greece.

\section{Acknowledgements}

The authors would like to thank MD. G. Rombopoulos and Dr. M. Kalogeropoulou for their contribution during the manuscript development.

\section{Competing interests}

The authors declare that they have no competing interests.

Ethics approval and consent to participate

Not applicable.

Funding

This study was funded by Novartis Hellas. 


\section{Publisher's Note}

Springer Nature remains neutral with regard to jurisdictional claims in published maps and institutional affiliations.

Received: 14 December 2015 Accepted: 23 August 2017 Published online: 06 September 2017

\section{References}

1. World Health Organization. Definition, diagnosis and classification of diabetes mellitus and its complications. Part 1: Diagnosis and classification of diabetes mellitus. World Health Organization: Geneva; 1999.

2. Stumvoll M, Goldstein BJ, van Haeften TW. Type 2 diabetes: principles of pathogenesis and therapy. Lancet. 2005;365:1333-46.

3. King H, Aubert RE, Herman WH. Global burden of diabetes, 1995-2025: prevalence, numerical estimates, and projections. Diabetes Care. 1998;21:1414-31.

4. Panagiotakos DB, Pitsavos C, Chrysohoou C, Stefanadis C. The epidemiology of type 2 diabetes mellitus in Greek adults: the ATTICA study. Diabet Med. 2005;22:1581-8.

5. World Health Organization. Definition and diagnosis of diabetes mellitus and intermediate hyperglycaemia. 2006.

6. Hogan P, Dall T, Nikolov P. Economic costs of diabetes in the US in 2002. Diabetes Care. 2003;26:917-32.

7. Zimmet P, Alberti KG, Shaw J. Global and societal implications of the diabetes epidemic. Nature. 2001;414:782-7.

8. American Diabetes Association. Economic costs of diabetes in the US in 2007. American Diabetes Association: Diabetes Care 2008, 31.

9. Migdalis I, Rombopoulos G, Hatzikou M, Manes C, Kypraios N, Tentolouris $\mathrm{N}$. The cost of managing type 2 diabetes mellitus in Greece: a retrospective analysis of 10-year patient level data "The HERCULES Study". Int J Endocrinol. 2015;2015:520759.

10. International Diabetes Federation. Global guideline for type 2 diabetes. 2012.

11. ADVANCE Collaborative Group, Patel A, MacMahon S, Chalmers J, Neal B, Billot L, Woodward M, Marre M, Cooper M, Glasziou P, Grobbee D, Hamet P, Harrap S, Heller S, Liu L, Mancia G, Mogensen CE, Pan C, Poulter N, Rodgers A, Williams B, Bompoint S, de Galan BE, Joshi R, Travert F. Intensive blood glucose control and vascular outcomes in patients with type 2 diabetes. N Engl J Med. 2008;358:2560-72.

12. Canadian Diabetes Association. Targets for glycemic control. Can J Diabetes. 2013;37:S302-3.

13. Foos V, Varol N, Curtis BH, Boye KS, Grant D, Palmer JL, McEwan P. Economic impact of severe and non-severe hypoglycemia in patients with type 1 and type 2 diabetes in the United States. J Med Econ. 2015;18:420-32.

14. Jeon HJ, Oh TK. Comparison of vildagliptin-metformin and glimepiridemetformin treatments in type 2 diabetic patients. Diabetes Metab J. 2011;35:529-35.

15. Ferrannini E, Fonseca V, Zinman B, Matthews D, Ahrén B, Byiers S, Shao Q, Dejager S. Fifty-two-week efficacy and safety of vildagliptin vs. glimepiride in patients with type 2 diabetes mellitus inadequately controlled on metformin monotherapy. Diabetes Obes Metab. 2009;11:157-66.

16. Clarke P, Gray A, Briggs A. Al. E: a model to estimate the lifetime health outcomes of patients with Type 2 diabetes: the United Kingdom Prospective Diabetes Study (UKPDS) Outcomes Model (UKPDS no. 68). Diabetologia. 2004;47:1747-59.

17. Viriato D, Calado F, Gruenberger J-B, Ong SH, Carvalho D, Silva-Nunes J, Johal S, Viana R. Cost-effectiveness of metformin plus vildagliptin compared with metformin plus sulphonylurea for the treatment of patients with type 2 diabetes mellitus: a Portuguese healthcare system perspective. J Med Econ. 2014;17:499-507.

18. International Diabetes Federation. IDF Diabetes Atlas, 6th Edition. 2013.

19. Hellenic Diabetes Association. Guidelines for the management of the diabetic patient. 2013.

20. NICE. Guide to the methods of technology appraisal 2013. 2013.

21. Monami M, Marchionni N, Mannucci E. Long-acting insulin analogues versus NPH human insulin in type 2 diabetes: a meta-analysis. Diabetes Res Clin Pract. 2008;81:184-9.
22. Ministry of Health. Positive reimbursement list, Governmental Gazette 2336B. 2014.

23. Ministry of Health. Unified Regulation for Health Care Benefits, Government Gazette 3054. 2012.

24. National Organization for health care services provision. Amendment of unified regulation for health care benefits, Protocol No 22473. 2013.

25. Ministry of Health. Diagnosis related groups and related tariffs, Governmental Gazette 946. 2012.

26. Maniadakis N, Kaitelidou D, Siskou O, Spinthouri M, Liaropoulos L, Fragoulakis B, Hatzikou M, Alexopoulosi D. Economic evaluation of treatment strategies for patients suffering acute myocardial infarction in Greece. Hellenic J Cardiol. 2005;46:212-21.

27. http://www.statistics.gr. Accessed July 2015.

28. Stafylas PC, Sarafidis PA, Grekas DM, Lasaridis AN. A cost-effectiveness analysis of angiotensin-converting enzyme inhibitors and angiotensin receptor blockers in diabetic nephropathy. J Clin Hypertens (Greenwich). 2007;9:751-9.

29. Clarke P, Gray A, Holman R. Estimating utility values for health states of type 2 diabetic patients using the EQ-5D (UKPDS 62). Med Decis Making. 2002:22:340-9.

30. Manns B, Meltzer D, Taub K, Donaldson C. Illustrating the impact of including future costs in economic evaluations: an application to endstage renal disease care. Health Econ. 2003;12:949-58.

31. Dennett SL, Boye KS, Yurgin NR. The impact of body weight on patient utilities with or without type 2 diabetes: a review of the medical literature. Value Health. 2008;11:478-86.

32. Currie CJ, Morgan CL, Poole CD, Sharplin P, Lammert M, McEwan P. Multivariate models of health-related utility and the fear of hypoglycaemia in people with diabetes. Curr Med Res Opin. 2006;22:1523-34.

33. Smith $D$, Gravelle $H$. the practice of discounting economic evaluation of health care interventions. CHE Technical Paper Series 19. 2000.

34. Danaei G, Finucane MM, Lu Y, Singh GM, Cowan MJ, Paciorek CJ, Lin JK, Farzadfar F, Khang Y-H, Stevens GA, Rao M, Ali MK, Riley LM, Robinson CA, Ezzati M. National, regional, and global trends in fasting plasma glucose and diabetes prevalence since 1980: systematic analysis of health examination surveys and epidemiological studies with 370 country-years and 2.7 million participants. Lancet. 2011;378:31-40.

35. Wild S, Roglic G, Green A, Sicree R, King H. Global prevalence of diabetes: estimates for the year 2000 and projections for 2030. Diabetes Care. 2004:27:1047-53.

36. Jönsson B. Revealing the cost of type II diabetes in Europe. Diabetologia. 2002:45:S5-12.

37. Candrilli SD, Meyers JL, Boye K, Bae JP. Health care resource utilization and costs during episodes of care for type 2 diabetes mellitus-related comorbidities. J Diabetes Complicat. 2015;29:529-33.

38. Jones S, Castell C, Goday A, Smith HT, Nicolay C, Simpson A, SalaunMartin C. Increase in direct diabetes-related costs and resource use in the 6 months following initiation of insulin in patients with type 2 diabetes in five European countries: data from the INSTIGATE study. Clinicoecon Outcomes Res. 2012;4:383-93.

\section{Submit your next manuscript to BioMed Central and we will help you at every step:}

- We accept pre-submission inquiries

- Our selector tool helps you to find the most relevant journal

- We provide round the clock customer support

- Convenient online submission

- Thorough peer review

- Inclusion in PubMed and all major indexing services

- Maximum visibility for your research

Submit your manuscript at www.biomedcentral.com/submit 